\title{
“O QUE OUVE?”: A MUSICALIZAÇÃO NAS ESCOLAS E O ALUNO SURDO
}

\section{ARTIGO ORIGINAL}

XAVIER, Talyta Beatriz Martins ${ }^{1}$

JUNIOR, Adival José Reinert ${ }^{2}$

XAVIER, Talyta Beatriz Martins. JUNIOR, Adival José Reinert. "O que ouve?": a musicalização nas escolas e o aluno surdo. Revista Científica Multidisciplinar Núcleo do Conhecimento. Ano 05, Ed. 07, Vol. 02, pp. 143-153. Julho de 2020. ISSN: 2448-0959, Link de

acesso:

https://www.nucleodoconhecimento.com.br/educacao/musicalizacao-nas-escolas

\section{RESUMO}

O presente artigo apresenta o trabalho de conclusão de curso de pós-graduação em metodologia do ensino da música. $O$ estudo baseia-se em bibliografias que abordam o tema música, surdez e educação musical. Essa pesquisa é de cunho qualitativo e se deu através de levantamentos bibliográficos, tendo como objetivo tratar da inclusão do aluno surdo nas aulas de música, visando uma educação musical sensorial, expondo a questão de ouvir a música pelas vibrações dos sons através da pele, sendo usada como mecanismo de aprendizagem e interação entre todos os alunos, sabendo que a música ajuda em vários processos do desenvolvimento infantil, inclusive da criança surda, desde que esta ferramenta seja utilizada de forma correta.

${ }^{1}$ Cursando especialização em metodologia do ensino da música, Licenciada em música.

${ }^{2}$ Orientador. Especialização em Teoria Psicanalítica. Especialização em Orientação, Supervisão e Gestão Escolar Democrática. Especialização em Docência do Ensino Fundamental, Médio e Superior. Graduação em Matemática. 
Palavras-Chave: Música, surdez, sensibilidade, educação.

\section{INTRODUÇÃO}

O que levou a fazer essa pesquisa foram perguntas que surgiram ao longo da minha vida acadêmica. Será que tudo que é estudado a respeito da musicalização infantil se aplica à criança surda? Será que todos os benefícios e contribuição da música para o desenvolvimento do ouvinte também fariam efeito se os surdos fossem musicalizados?

Esta pesquisa busca entender o processo da musicalização nas escolas, bem como isto deve ocorrer quando a classe for composta por alunos surdos. Aborda ainda a importância da musicalização na infância, a função do intérprete de Libras em sala de aula e os desafios do professor de música no que tange a como o aluno surdo sente a música.

Segundo Haguira-Cervellini (2003) afirma, a maioria dos estudos na área da surdez é referente a questões clínicas, no entanto existe poucos estudos a respeito do desenvolvimento na questão da sensibilidade da música. Nesse sentido, o maior desafio é quebrar o preconceito que vem se perpetuando ao longo dos anos de que a música é uma arte apenas para ouvintes, quando, na verdade, ela pode ser sentida por qualquer pessoa, independente do seu estado físico ou emocional.

Um dos conceitos mais comuns de música diz que ela é uma arte que meche com as emoções, que fala com a alma e consegue atrair e unir pessoas de diferentes povos e culturas. Sendo assim, o surdo tem todo o direito de sentir esse prazer que só a música é capaz de proporcionar. Além disso, ela proporciona outros benefícios que serão abordados ao longo do texto, de extrema importância para educação, formação e desenvolvimento da criança, os benefícios são para ambos surdos e ouvintes, o que irá diferenciar será a forma de se trabalhar o som em sala para que todos os alunos sejam alcançados e desfrutem da serventia desta arte. 
Muitos acreditam que não é possível que o surdo faça música pelo fato de não poder escutar, mas ao decorrer dos anos vem crescendo o número de estudos e pesquisas a respeito da educação musical do surdo, mostrando que o surdo pode sim fazer e desfrutar da música, porque se trata também de uma arte sensorial. Apesar de não ouvir os sons, os surdos os sentem através do corpo, ou seja, a música possui vibrações, e estas podem ser sentidas, proporcionando a eles, ao contrário do que se pensa comumente, o contato com a educação musical.

\section{A MUSICALIZAÇÃO NAS ESCOLAS E O ALUNO SURDO}

\subsection{A MUSICALIZAÇÃO NAS ESCOLAS}

A música é a arte que permite a expressão por meio dos sons. Segundo Med (1996, p.11): "Música é a arte de combinar os sons simultânea e sucessivamente, com ordem, equilíbrio e proporção dentro do tempo." Com essa definição vemos que para se fazer música é necessário a utilização dos sons.

Sabemos que a anos são feitos estudos sobre a importância da musicalização nas escolas de educação básica. Estas pesquisas mostram os benefícios da música para o cérebro da criança e a importância deste contato para o desenvolvimento infantil.

Embora se diga que a percepção da música se localize no hemisfério direito do cérebro, sabe-se hoje que o aprendizado musical depende dos dois hemisférios, uma vez que ele é interdependente de outras funções cerebrais, como a memória, a linguagem verbal, a resolução de problemas e a análise, entre outras. A propósito, sabe-se hoje que o cérebro do músico treinado é diferente do cérebro do não-músico. (ILARI, 2003, p. 9)

A música ajuda no desenvolvimento geral e em várias áreas do cérebro, como coordenação motora, por exemplo. Com base neste e em outros benefícios que a música proporciona é que é defendido o ensino da música nas escolas de educação básica, de modo que seja inserida no currículo escolar e faça parte do cotidiano dos alunos. De acordo com Souza (2010, p.98): "As crianças quando brincam ou interagem com o universo sonoro, acabam descobrindo mesmo que de maneira simples, formas diferentes de fazer música." 


\subsection{A MUSICALIZAÇÃO E O INTÉRPRETE DE LIBRAS}

No ensino regular quando se tem um ou mais alunos surdos em sala de aula é adotada a presença de um intérprete de língua brasileira de sinais (Libras). Segundo Lacerda e Poletti (2004, p.1): "Quando se insere um intérprete de língua de sinais na sala de aula abre-se a possibilidade de o aluno surdo receber a informação escolar em Libras, através de uma pessoa com competência nesta língua."

O surdo tem o direito ao intérprete para que possa entender os assuntos ministrados em aula e ver e receber os conteúdos na sua língua materna, facilitando assim o aprendizado.

Você já esteve em uma sala de aula em que todos os alunos, incluindo o professor falasse chinês menos você? Para entender o que estaria sendo ensinado você precisaria ao menos de um intérprete que conseguisse traduzir do chinês para o português.

Assim também acontece nas escolas onde tem alunos surdos inseridos em uma sala de aula em que professores e alunos ouvintes não fazem uso da língua de sinais. Contudo, este assunto vai além disto: o intérprete muitas vezes não possui conhecimento aprofundado em determinado conteúdo, assim falhando na transmissão do que esteja sendo ensinado pelo professor, ficando, assim, defasado, o aprendizado do aluno surdo.

Trazendo para a questão da musicalização, o intérprete de Libras não garantiria a transmissão e conteúdo abordado pelo professor de música. Além disto, se o professor de música não tem nenhum conhecimento a respeito do aluno surdo, a metodologia preparada apenas para alunos ouvintes provavelmente não alcançaria de forma satisfatória aos alunos surdos presentes em sala.

Agora, por exemplo, imagine que naquela mesma escola onde alunos e professores falam chinês a aula ministrada seja de música, porém o intérprete não tem o mínimo conhecimento de música e muitas vezes não consiga transmitir o ensino 
corretamente. A aula de música seria sem sentido para o aluno surdo, por isso, se o professor de música não fala a língua brasileira de sinais, é de extrema importância a presença de um intérprete com conhecimento musical, para que o assunto possa ser interpretado na íntegra.

\subsection{A MÚSICA E O ALUNO SURDO}

A surdez refere-se ao nível de perda auditiva que o indivíduo possa ter, sendo a maior delas a perda auditiva profunda. Ou seja, a criança surda tem dificuldade para comunicar-se por meio da audição. A perda de audição profunda leva o indivíduo a ouvir o som mais suave à $95 \mathrm{~dB}$, que é um som consideravelmente forte, como exemplo uma moto sem escapamento ou a bateria de uma escola de samba.

Como vimos no início do texto, para se fazer música necessitamos do som. Mas como iremos abordar conteúdos relacionados ao som se em nossa sala de aula tivermos alunos com baixa adição ou até mesmo com perda de audição profunda?

Como o sujeito surdo pode ter acesso a essa arte essencial? Por meio de aparelhos amplificadores de som e da percepção corporal, esse sujeito pode usufruir a música. Ela pode estar presente na vida, enriquecendo suas experiências e, basicamente, possibilitando a expressão e vivência de estados afetivos, de prazer e de autorealização, contribuindo para a construção positiva de uma auto-imagem e para o seu desenvolvimento emocional. (HAGUIARA-CERVELLINI, 2003, p.81)

Segundo a autora, o surdo pode usufruir da música por meio da amplificação do som ou da percepção corporal. Visto que muitos surdos não gostam de aparelhos de amplificação do som e se opõe a eles, seria viável, nas aulas de música darmos ênfase na percepção corporal do surdo. Porém será que independente do grau de surdez é possível se trabalhar a música?

Numa trajetória com oito crianças surdas de quatro anos, durante um ano letivo, cheguei à conclusão de que, independente do grau de perda auditiva, são sensíveis à música, que a vivência da música possibilita a canalização de estados conflituosos e de disputa para o toque de instrumentos musicais e para a dança, que gradualmente surgem manifestações rítmicas e espontâneas, chegando até a criar improvisos 
rítmicos e melódico-vocais, enfim, que a vivência da música propiciou e tornou visíveis a descontração, a liberdade, a criatividade, a comunicação, a afetividade e a alegria das crianças. (HAGUIARACERVELLINI, 2003, p.81)

Como visto, não importa o grau de surdez é sempre possível trabalhar música com crianças surdas. Os benefícios trazidos pela música a crianças ouvintes também são proporcionados a crianças surdas se trabalhados de maneira correta, atentando para a percepção corporal do surdo, trazendo descontração, coordenação motora, trabalho em equipe entre outros benefícios da musicalização infantil.

Ter uma criança surda em sala de aula não será impedimento para a abordagem do conteúdo proposto. É importante que o professor de música se atente e se aprofunde neste assunto, buscando sempre instrumentos e sons com mais vibrações, para facilitar esta percepção corporal, além de buscar um ambiente adequado para as aulas.

\subsection{O DESAFIO PARA O EDUCADOR MUSICAL}

Gostaria agora de abordar o desafio para o professor de música ao receber um ou mais alunos surdos em sala. O professor precisa estar atento, principalmente se sua classe é de educação infantil, em que os alunos estão desenvolvendo a fala. Essa observação do professor é de extrema relevância, para que possa trabalhar em prol da necessidade de cada aluno, facilitando os desafios enfrentados em sala.

O educador musical precisa estar atento se possui um aluno com perda auditiva, precisa fazer modificações para melhor atender aquele aluno e a classe como um todo. Se o professor identifica alguma coisa diferente no aluno é importante comunicar aos pais para que isto seja investigado, pois com maior contato do professor com o aluno em sala é comum que o professor perceba se algo está fora do normal.

A deficiência auditiva representa um contingente substancial dos diagnósticos com os quais os professores terão contato em sala de aula. Entendê-la e reconhecê-la são passos primordiais para que se otimize o rendimento do aluno que a apresente, diminuindo, assim, as dificuldades 
que este enfrentará numa sala composta por alunos com e sem deficiência. (LOURO, 2012, p.169).

Vemos assim, a importância do acompanhamento do professor, porque, sendo reconhecido o problema serão trabalhadas as possibilidades e o que pode ser feito de maneira a acrescentar no aprendizado e desenvolvimento do aluno. Quanto antes houver o diagnóstico o educador musical se preparará para ministrar as suas aulas.

Segundo Louro (2012, p.178): "O "não-ouvir" numa realidade como a nossa, essencialmente auditiva e oral, representa um problema complicado, tanto do ponto de vista social, quanto do cultural ou pedagógico." Ou seja, como ensinar música para uma criança que não ouve? Por isto é necessária uma maior atenção do professor, para que se possa preparar a sala de aula para que a percepção corporal do surdo seja explorada ao máximo. Pode-se fazer uso de instrumentos que vibrem mais, como é o caso de instrumentos de percussão.

Gostaria de citar, como exemplo, o projeto Banda Música do Silêncio do professor Fábio Bonvenuto do Estado de São Paulo. O projeto ensina música a alunos surdos da EMEE Madre Lucie Bray e EMEF Marechal Rondon. Este projeto, na prática, mostra que é sim possível o surdo fazer música, gostar de música e até ser integrante de uma banda. Este é apenas um entre tantos projetos que envolvem música e surdos, como também é o caso do Instituto Sons do Silêncio, que desenvolve esse trabalho de ensino de música para surdos e fica em Recife-PE.

É importante o professor se atentar para o espaço onde ocorrerá a aula, para que o ambiente seja satisfatório tanto para ouvintes quanto para surdos. Por isso é importante uma boa acústica para que possam ser percebidas melhor as vibrações dos sons. Outro ponto que também ajuda é o piso da sala, para ajudar que as vibrações se propagem. Como afirma Louro:

Quando possível, as atividades devem se realizar sobre um tablado, oco e distanciado cerca de 15 centímetros do chão, a fim de que (através da vibração da madeira) fique mais fácil, para os alunos, a percepção das vibrações dos instrumentos. Em matéria de equipamento, obviamente as caixas acústicas (e toda aparelhagem de som) devem ser de boa 
qualidade e com potência suficiente para fazer vibrar o tablado. (LOURO, 2012, p.96)

Quanto mais possa fazer vibrar melhor para o aluno sentir o som, isto também vale para o ensino de instrumentos. Os instrumentos que vibram mais serão mais fáceis o aprendizado.

\subsection{A SENSIBILIDADE À MÚSICA}

"A criança surda, independente do seu grau de perda auditiva, é sensível à música, gosta dela e deseja-a, manifestando-se, tocando, dançando e cantando espontaneamente." (HAGUIARA-CERVELLINI, 2013, p.12)

Para a autora a criança surda é sensível à música independe de sua perda auditiva, no entanto esta sensibilidade deve ser instigada, o que muitas vezes não acontece. Quando pais e até mesmo professores descobrem que a criança tem alguma deficiência auditiva, costumam restringi-la da música.

A descrença de pais e professores quanto a essa possibilidade do DA justifica a ausência ou a restrição da música no seu cotidiano. [...] Mães que tinham por hábito ligar o rádio próximo ao bebê, para alcama-lo ou adormecê-lo, afirmam ter deixado de fazê-lo, tão logo descobriram que ele era surdo. (HAGUIARA-CERVELLINI, 2013, p. 13)

Esta restrição é que muitas vezes afasta a criança surda da música. Essa descrença dos pais e professores afeta a aprendizagem musical, pois quanto mais cedo houver e permanecer este contato, melhor será o desenvolvimento desta sensibilidade à música.

Por isso é bom que a criança seja sempre exposta aos sons, mesmo sons do cotidiano, mesmo que sejam sons imperceptíveis por eles, fazendo com que eles observem cada ambiente e vão criando reconhecimentos sonoros através de sua percepção musical.

O maior obstáculo que rodeia a relação música-surdo é o conceito préestabelecido de que a música foi feita apenas para aqueles que ouvem. Há pessoas, contudo, que compartilham de outra opinião: a de que a 
música não foi feita apenas para ser ouvida, mas também sentida, percebida e vivida. Desde criança, o surdo pode aprender a perceber os sons que o rodeiam. (OLIVEIRA, 2014, p.5)

Ou seja, o vale que separa a música dos surdos são concepções a base de achismo de que música é apenas para ouvintes. Graças a muitos pesquisadores essas concepções vêm sendo quebradas e a música tem sido introduzida no cotidiano do surdo.

\section{CONSIDERAÇÕES FINAIS}

As atividades musicais auxiliam no desenvolvimento do cérebro das crianças. Segundo llari (2003) a música sendo trabalhada acompanhada de movimentos corporais podem estimular até seis sistemas do cérebro. A música estimula e ajuda no desenvolvimento da criança, por isso a importância dela na educação básica. A grande questão, neste sentido, era como tê-la em escolas com alunos surdos?

Ao decorrer da pesquisa foi possível derrubar os conceitos pré-estabelecidos de que música só poderia acontecer para alunos ouvintes, mostrando que os benefícios da música são para surdos também. A música vai além dos sons que ouvimos, é possível sentir e aprender através das vibrações que os sons produzem, permitindo ao surdo ser educado musicalmente, aprender instrumentos musicais, sentir e fazer música.

Vimos, ainda, que o professor deverá se atentar a questão da percepção corporal, usando metodologias que facilitem essa percepção tornando o aprendizado musical mais fácil e prazeroso para essas crianças.

A pesquisa nos leva a refletir, como educadores musicais, na importância de incluir nossos alunos independente de qualquer situação. Temos que sempre buscar conhecimento para atender cada aluno em suas necessidades, ajudando na compreensão dos conteúdos abordados, levando a musicalização infantil com o intuito de contribuir para a formação e desenvolvimento dos alunos, sempre acreditando que por meio da música podemos levar mudança e melhoria. 


\section{REFERÊNCIAS}

GOHN, Maria Da Glória. O Papel da música na educação infantil. Eccos Revista Científica, Universidade Nove de Julho, São Paulo, V. 3, N. 2, p. 85-103, jul/dez. 2010.

HAGUIARS-CERVELLINI, Nadir. A musicalidade do surdo: representação e estigma. São Paulo: Plexus Editora, 2003.

ILARI, Beatriz. A música e o cérebro: algumas implicações do neurodesenvolvimento para a educação musical. Revista da ABEM, Porto Alegre, v.9, p. 7-16, setembro. 2016.

LACERDA, Cristina B.F.; POLETTI, Juliana.E. A escola inclusiva para surdos: a situação singular do intérprete de língua brasileira de sinais. Disponível em: $<$ www.anped.org.br/biblioteca/item/escola-inclusiva-para-surdos-situacao-singulardo-interprete-de-lingua-de-sinais>. Acessado em: 20 de fevereiro de 2020.

LOURO, Viviane. A aprendizagem musical face à deficiência. In: Fundamentos da aprendizagem musical da pessoa com deficiência. São Paulo: Editora Som, 2012. P. 119-273

MED, Bohumil. Teoria da Música. Brasília-DF: Musimed, 1996.

OLIVEIRA, Hilka Cibelle da Cruz. O desenvolvimento do sujeito surdo a partir da música. Revista Virtual de Cultura Surda. Editora Arara azul, setembro de 2014. Acessado em $<$ https://editora-araraazul.com.br/site/admin/ckfinder/userfiles/files/20\%20Artigo\%20para\%20Revista\%201 4\%20de\%20autoria\%20de\%20HILKIA\%20OLIVEIRA.pdf>. Acesso em: 23 de fevereiro de 2020.

SOUZA, Carlos Eduardo de; JOLY, Maria Carolina Leme. A importância do ensino musical na educação infantil. Caderno de Pedagogia, 2007.

Enviado: Junho, 2020. 
Aprovado: Julho, 2020. 